\title{
False positive FTA-ABS results in patients with genital herpes
}

\author{
J. T. WRIGHT*, A. W. CREMER†, AND G. L. RIDGWAY† \\ From the Departments of Genitourinary Medicine ${ }^{\star}$ and Microbiology†, University College Hospital, London
}

The absorbed fluorescent treponemal antibody test (FTA-ABS) is a sensitive and specific test for syphilis and other treponemal diseases. Sera are first treated with a 'sorbent' consisting of a heated and concentrated filtrate in which Reiter treponemes have been grown; this neutralizes the effect of group antitreponemal antibody present in many normal sera (Deacon, Lucas, and Price, 1966). False positive reactions to the FTA-ABS are rare, but have been found in sera containing abnormal macroglobulins or antinuclear factors (Mackey, Price, Knox, and Scotti, 1969; Jokinen, Lassus, and Linder, 1969). A beaded staining of treponemes may be given by sera from some patients with systemic lupus erythematosus (Kraus, Haserick, Logan, and Bullard, 1971). No consistently false positive reactions to the FTA-ABS have been described for other diseases. However, Király, Jobbágy, and Kováts (1967) reported a few patients with genital lesions not due to syphilis whose sera were reactive with the FTAABS test. This paper reports the results found in a group of patients with genital herpes whose sera were examined with the FTA-ABS test.

\section{Material and methods \\ Clinical methods}

The patients were seen between November, 1973, and March, 1974. A clinical diagnosis of genital herpes was made from the appearance of characteristic vesicles followed by shallow painful ulcers on the penis or vulva. Specimens of material from the lesions for culture of herpes simplex virus (HSV) were collected with cotton wool swabs, which were broken into virus transport medium and immediately sent to the laboratory. Blood for serological studies was taken at the patient's first attendance and, in many instances, at subsequent attendances also. Other sexually-transmitted diseases, if present, were diagnosed and treated by conventional methods.

\section{Microbiological methods}

Tissue culture for HSV was performed in human embryonic fibroblast or Hep2 cell lines. Serological tests for syphilis were performed on all sera as follows:

Received for publication March 14, 1975

Address for reprints: Dr J. T. Wright, University College Hospital, Gower Street, London WCIE 6AU (a) Rapid Plasma Reagin Test (RPR), using the 'Brewer Diagnostic Kit' marketed by Becton Dickinson Ltd., and the Treponema pallidum Haemagglutination Assay (TPHA) by the method of Rathlev (1967).

(b) The FTA-ABS test was undertaken by the technique of Hunter, Deacon, and Mayer (1964), using materials supplied by Wellcome Reagents Ltd., the sorbent being supplied by Difco Laboratories. The antigen is supplied by Baltimore Biological Laboratories and is marketed in this country by Becton Dickinson.

(c) In addition, some sera were also examined by the Venereal Diseases Reference Laboratory, Ashfield Street, London, E.1, where the tests used were Cardiolipin Wasserman reactio., Venereal Disease Research Laboratory slide test, Reiter protein complement-fixation test, FTA-ABS test, and sometimes the Treponema pallidum immobilization test. The techniques used in the laboratory for these tests have been described by Wilkinson, Taylor, McSwiggan, Turner, Rycroft, and Lowe (1972).

\section{Results}

During the study period 32 patients were seen with genital herpes confirmed by virus culture. Of these, 25 were men and seven were women. All the patients were Caucasian. None gave a past history of treponemal disease and there was no clinical evidence of old or untreated syphilis in any patient. Dark-ground examination of material from the lesions carried out in twenty patients was negative for $T$. pallidum in every case. Of 32 patients with genital herpes, one had co-existing gonorrhoea, one non-specific genital infection, two trichomoniasis, and two candidosis.

\section{Serological results}

Sera from all 32 patients were examined with the RPR, TPHA, and FTA-ABS tests. The RPR and TPHA were negative in every case, but the FTA-ABS test was reactive in six patients and weakly reactive in a further seven. Seven of these thirteen reactive or weakly reactive sera were examined at the Venereal Diseases Reference Laboratory, where all serological tests were negative.

Of the thirteen patients with genital herpes whose sera were reactive to the FTA-ABS test, four defaulted and were not available for re-examination, 
six were followed-up for 8 weeks, and three for 4 weeks. In four of the six patients followed for 8 weeks, the FTA-ABS test became non-reactive, and in two it remained reactive. In one of the three patients followed for 4 weeks, the serum became nonreactive, but in two it remained reactive. The RPR and TPHA remained negative in all patients throughout the follow-up period.

\section{Discussion}

We have observed that the FTA-ABS test may be reactive or weakly reactive in some patients during the acute phase of genital herpes. We found no history or clinical evidence of syphilis in these patients; dark-ground examination for $T$. pallidum, when performed, was negative, and other serological tests for syphilis (RPR and TPHA) were uniformly negative, as were all serological tests carried out at the Venereal Diseases Reference Laboratory. Thus, a false positive reaction with the FTA-ABS test seems to be possible with genital herpes. Reactivity in the FTA-ABS test may occur in collagen diseases, either as fluorescent beading on the treponeme or as a uniform fluorescence, probably because of the presence of antibody to deoxyribonucleic acid (Kraus and others, 1971). HSV is a DNA virus and it is possible that, in addition to the formation of antibody to the virus, anti-DNA antibody is formed and that this is incompletely absorbed by commerciallyprepared sorbent, becomes attached to the DNA of the treponemes used in the reaction, and is detected by immunofluorescence; we have also noticed false positive FTA-ABS test results in a patient with vaccinia infection, the cause of which is another DNA virus. We are attempting to elucidate the problem by removing the DNA from the Nichols strain of $T$. pallidum before use by the addition of DNA-ase, and by testing the sera for anti-DNA antibody.

In general, serological results from our laboratory and those from the Venereal Diseases Reference Laboratory are in close agreement, and the difference between our results may be due to the sorbing agent used. In our FTA-ABS test we use a commerciallyprepared sorbent. In the Venereal Diseases Reference Laboratory, a sorbent prepared in the laboratory by the standard technique is used. All sera which give an unexpected positive or doubtful result are reexamined; a Reiter sonicate is then used as the absorbing agent and the sera tested against both $T$. pallidum and Reiter treponemes as antigens. Results are accepted as valid only if there is definite fluorescence with $T$. pallidum but none with Reiter treponemes, showing that all antibody which can react with the Reiter antigen has been absorbed. Of the sera which we had found reactive by the FTAABS test, all but one gave negative results in the Venereal Diseases Reference Laboratory with sorbent, so were not re-tested with Reiter sonicate. The remaining serum gave a weak reaction with sorbent but was negative when re-tested with sonicate; a second specimen from the same patient was negative with sorbent.

Our results indicate that when the FTA-ABS test is performed by the standard technique using a commercially-prepared sorbent it may occasionally be reactive in patients with genital herpes. It is conceivable that in these circumstances syphilis may be incorrectly suspected or diagnosed, particularly if dark-field examination is omitted, as has recently been advocated (Duncan, Knox, and Wende, 1974). However, awareness of the possibility of occasional false positive FTA-ABS in genital herpes, combined with the use of other serological tests, dark-field examination for $T$. pallidum, and culture for HSV, should enable an accurate diagnosis to be made.

We are very grateful to Dr. A. E. Wilkinson for providing details of the techniques used in the Venereal Diseases Reference Laboratory, for examining sera from our patients, and for his helpful advice. We are also grateful to Dr. E. J. Stokes for her advice in preparing this report and to Dr. J. D. Oriel for allowing us to study patients under his care.

\section{References}

Deacon, W. E., Lucas, J. B., and Price, E. V. (1966) F. Amer. med. Ass., 198, 624

DunCan, W. C., KNOX, J. M., and Wende, R. D. (1974) Ibid., 228, 859

HunTER, E. F., DeAcon, W. E., and MAYER, P. E. (1964) Publ. Hlth Rep. (Wash.), 79, 410

JokIneN, E. J., LASsus, A., and LINDE, R. (1969) Ann. clin. Res., 1,77

KirÁly, K., JobBágy, B. S., and Kováts, L. (1967) F. invest. Derm., 48, 98

Kraus, S. J., Haserick, J. R., Logan, L. C., and Bullard, J. C. (1971) F. Immunol., 106, 1665

MACKey, D. M., Price, E. V., KNOX, J. M., and Scotti, A. (1969) f. Amer. med. Ass., 207, 1683

Rathlev, T. (1967) Brit. F. vener. Dis., 43, 181

Wilkinson, A. E., Taylor, C. E. D., McSwiggan, D. A., Turner, G. C., Rycroft, J. A., and LOWE, G. H. (1972) Public Health Laboratory Service Monograph (Series 1). HMSO, London 